\title{
Transitory Regimes and Their Effects on the Insulation of High Power Transformers
}

\author{
Marian Duta, Maria Cristina Nitu*, Marcel Nicola \\ Research and Development Division/National Institute for Research Development and Testing in Electrical Engineering - ICMET, Craiova, \\ Romania \\ Email address: \\ marianduta@icmet.ro (M. Duta), cristinamarianitu@yahoo.com (M. C. Nitu), marcel_nicola@yahoo.com (M. Nicola) \\ ${ }^{*}$ Corresponding author
}

\section{To cite this article:}

Marian Duta, Maria Cristina Nitu, Marcel Nicola. Transitory Regimes and Their Effects on the Insulation of High Power Transformers. American Journal of Electrical and Computer Engineering. Vol. 4, No. 2, 2020, pp. 72-80. doi: 10.11648/j.ajece.20200402.16

Received: November 6, 2020; Accepted: November 18, 2020; Published: December 4, 2020

\begin{abstract}
Transformers are the most important pieces of equipment in the electricity transmission and distribution system. Their importance derives both from their high cost and from the fact that they ensure a proper operation of the national power system. The transitory regimes generated during the operation of transformers, such as the overvoltage caused by the lightning impulse and the transient currents when wiring the transformers result in mechanical stress, thermal stress and electrical stress in transformers. These stresses lead to the aging of the insulation system, to avoid possible damage or even the decommissioning of transformers, this paper presents analytical methods for determining the overvoltage transmitted between the windings of transformers due to the lightning impulse and the transient currents that occur when connecting the transformers. The studies were performed on two high power transformers: TTOS-OFAF of $40 \mathrm{MVA}, 1236.3 \mathrm{kV}$ was used to determine the overvoltages that propagate at the windings of the transformer subjected to lightning impulse, and on TTOS-OFAF of 15 MVA, $10.5 / 6.3 \mathrm{kV}$ was performed the study on the effects of the appearance of the connection current on the transformer insulation. The studied phenomena can have a negative impact on the transformer operation.. The results obtained have been validated by laboratory tests, and they can be used to determine the measures to be taken in order to avoid possible damages as of the time of the transformer implementation in the system.
\end{abstract}

Keywords: Overvoltage, Lightning Impulse, Inrush Current, Power Transformer, Insulation

\section{Introduction}

The impact of transient phenomena on the operation of high-power transformers is a current concern starting with their design stage to ensure proper insulation.

This paper deals with two of the transitory regimes encountered during the operation of transformers: the overvoltage propagating in the windings of transformers when subjected to the lightning impulse, and the transient current that occurs when wiring the transformers [1-8].

The paper includes analytical methods for determining the overvoltage transmitted between the windings of transformers due to the lightning impulse and the transient currents that occur when connecting the transformers.

Both transitory regimes presented in this paper generate mechanical stress, thermal stress and electrical stress in transformers.
To benefit from an optimal maintenance program, the active part of the transformer (magnetic core and windings) must be assessed as follows [1, 8-15]:

1. the thermal assessment is aimed at the faster-than-anticipated aging due to the excess temperatures caused by the hot spot of the winding, the hot spot in the core and the defects of paper-insulated hot metals;

2. dielectric evaluation follows the process of degradation of solid / liquid insulation due to high thermal or electrical voltage, moisture in the paper / dielectric liquid, manufacturing defects and contamination with conductive particles;

3. the mechanical assessment is aimed at the disintegration of the structure in the core, the windings and the solid insulation, due to one of the many reasons, such as the strong electromagnetic forces resulting from the flow of 
short-circuit current through the windings; the mechanical deformation of the windings due to the shocks during transportation, installation or during system failures, etc.; and the degradation of solid insulating materials [16-25].

Some of the operations concerning the maintenance of power transformers can be established following the modeling of the transient phenomena, starting with the design stage. For these reasons, this paper assists the users of transformers in using proper protections for their implementation in the system and in avoiding possible failures, e.g. the controlled connection of transformer phases, to avoid high currents when wiring the transformer.

\section{Overvoltages Transmitted Between the Windings of Transformers Due to the Lightning Impulse}

The transient phenomenon caused by the lightning impulse in the windings of a transformer is difficult to fit into a model, because both the amplitude and the frequency of the energizing voltage are variable over time. In addition, there is no consensus on the contribution of the magnetic core in determining the amplitude, the frequency of oscillation and the attenuation of the resulting signal in various parts of the windings [8-14].

The coupled circuit model was used to carry out the analysis of the overvoltages transmitted between the windings of high-power transformers. For the magnetic circuit, this model uses as concentrated parameters the leakage inductances and current sources whose amplitude depends on the electric current generated in the electrical circuit.

The magnetic circuit allows the determination of the magnetic fluxes, whose derivatives supply electromotive force to the electrical circuit. This analysis model allows for the concentrated parameters of the two circuits to be easily obtained, provided that the design data, the overall dimensions of the transformer are known.

\subsection{Determination of the Electrical Circuit Parameters}

\subsubsection{Determination of the Electrical Circuit Parameters for the Low Voltage Winding}

The winding resistance is assigned the d.c. measured resistance value, which can be calculated according to the relation [8-10]:

$$
R_{J T}=\rho_{c u} \frac{n_{J T} \cdot \pi \cdot D_{m J T}}{S_{c u J T}} \frac{1}{n_{p J T}}
$$

where: $\rho_{\mathrm{cu}}$ - is the resistivity of copper;

$\mathrm{n}_{\mathrm{JT}}$ - number of turns of the LV winding;

$\mathrm{D}_{\mathrm{mJT}}$ - average diameter of a LV turn; $\mathrm{S}_{\mathrm{cuJT}}$ - area of the LV winding conductor section;

$\mathrm{n}_{\mathrm{pJT}}$ - number of conductors in parallel.

At high frequencies, the impedance of the copper wire increases due to the skin effect, but we consider that the iron loss resistance has the greatest share in achieving the damping coefficient. This approximation is made to introduce a quantity that can be determined experimentally.

In terms of the capacitances inserted into the electrical circuit model, only the capacitances of the coils to the magnetic core will be taken into consideration.

The expression of the capacitance between two concentric cylinders was used the equation 2 where [8]:

$\mathrm{H}_{\mathrm{JT}}$ - is the height of the coil;

$\mathrm{D}_{\mathrm{i}}$ - the diameter of the cylinders which make up the insulation between the coils and the core;

$\varepsilon_{\mathrm{ri}}$ - the relative permittivity of the insulating medium.

$$
C_{J T}=H_{J T} \frac{2 \cdot \pi \cdot \varepsilon_{o}}{\sum_{i} \frac{1}{\varepsilon_{r i}} \ln \frac{D_{i}+1}{D_{i}}}
$$

The following parameters were neglected:

1. the capacitance between turns, because at high frequencies, it has a negligible impedance to the resistance of the copper wire;

2. the capacitances to the tank and between the adjacent low voltage windings, because they have negligible values compared to the values of the capacitance to the magnetic core.

\subsubsection{Determination of the Electrical Circuit Parameters for the High Voltage Winding}

The winding resistance is determined based on the equation [8-10]:

$$
R_{I T}=\rho_{c u} \frac{n_{I T} \cdot \pi \cdot D_{m I T}}{S_{c u I T}} \frac{1}{n_{p I T}}
$$

where: $\mathrm{n}_{\mathrm{IT}}$ is the number of turns of the HV winding;

$\mathrm{D}_{\text {mIT }}$ - average diameter of a $\mathrm{HV}$ turn;

$\mathrm{S}_{\text {culT }}$ - area of the HV winding conductor section;

$\mathrm{n}_{\text {pIT- }}$ number of conductors in parallel.

The notations used to determine the capacitances involved in transmitting the overvoltages between the windings of the transformer are in accordance with those in Figure 1.

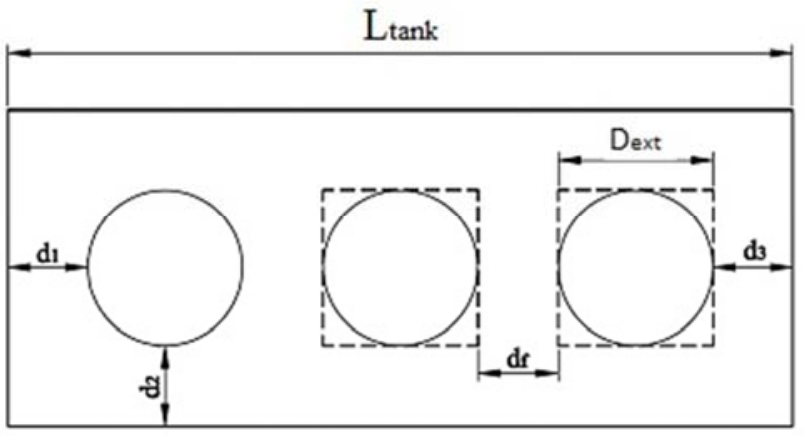

Figure 1. Layout of the HV winding to the transformer tank.

1. Capacitance of the lateral phases to the tank [8-10]: 


$$
C_{I T_{L}-C}=\frac{1}{2} \varepsilon_{o} \cdot \varepsilon_{r} \cdot H_{I T} \cdot D_{e x t}\left(\frac{2}{d_{2}}+\frac{1}{d_{1}}\right)
$$

2. The capacitance of the central phase to the tank [8-10]:

$$
C_{I T_{C}-C}=\frac{1}{2} \varepsilon_{o} \cdot \varepsilon_{r} \cdot H_{I T} \cdot D_{e x t} \frac{1}{d_{1}}
$$

3. The capacitance of the high voltage winding neutral to the tank [8-10]:

$$
C_{N}=2 \cdot C_{I T_{L}-C}+C_{I T_{C}-C}+C_{n}
$$

where: $C_{n}$ is the capacitance of the neutral to the tank.

4. The capacitance between the central phase and the lateral phases [8-10]:

$$
C_{I T_{C}-I T_{L}}=\frac{1}{2} \varepsilon_{0} \cdot \varepsilon_{r} \cdot H_{I T} \cdot D_{e x t} \frac{1}{d_{f}}
$$

The capacitance between the high voltage winding and the low voltage winding is calculated based on the relation (2).

The voltage distribution along the high-voltage winding is non-linear when energized by a lightning impulse in the electrical circuit, it is considered a capacitance equal to one third of the value of the $\mathrm{C}_{\mathrm{IT}-\mathrm{JT}}$ capacitance situated between the inputs of the high-voltage, and respectively the low voltage windings.

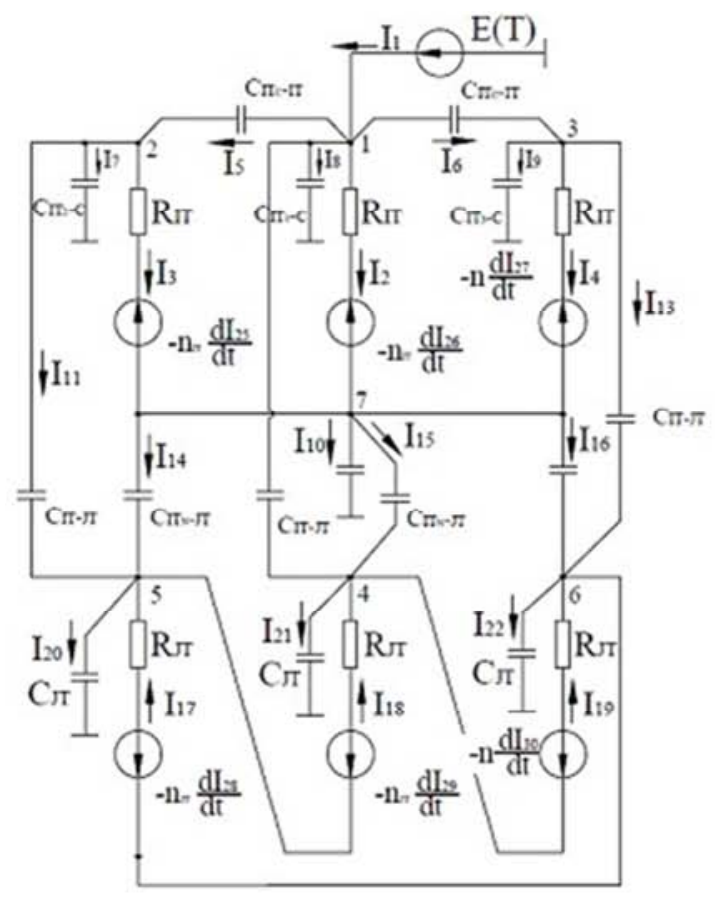

\subsection{Determination of the Magnetic Circuit Parameters}

The magnetic field lines generate a fascicle flux in the cross section of the magnetic core $\Phi$. This flux associated with the number of turns of the high voltage winding $\mathrm{n}_{\mathrm{IT}}$ and the number of turns of the low-voltage winding $\mathrm{n}_{\mathrm{JT}}$ represents the total flux:

$$
\begin{gathered}
\varphi_{t I T}=n_{I T} \cdot \varphi \\
\varphi_{t J T}=n_{J T} \cdot \varphi
\end{gathered}
$$

The stray magnetic field lines of the high-voltage winding in relation to the low-voltage winding are partially closed through the magnetic core. These lines generate a total stray flux/magnetic leakage $\Phi_{\text {tIT-JT. }}$ The following relation is obtained by applying the electromagnetic induction law:

$$
R_{I T} \cdot i_{I T}-u_{I T}=-\frac{d}{d t}\left(\varphi_{t I T}+\varphi_{t I T-J T}\right)
$$

where:

$\mathrm{i}_{\mathrm{IT}}$ represents the current flowing through the HIV winding;

$\mathrm{u}_{\mathrm{IT}}$ - the $\mathrm{HV}$ winding terminal voltage, considering that:

$$
\varphi=\frac{n_{I T} \cdot i_{I T}+n_{J T} \cdot i_{J T}}{R_{F e}}
$$

where $R_{F e}$ is the magnetic core reluctance.

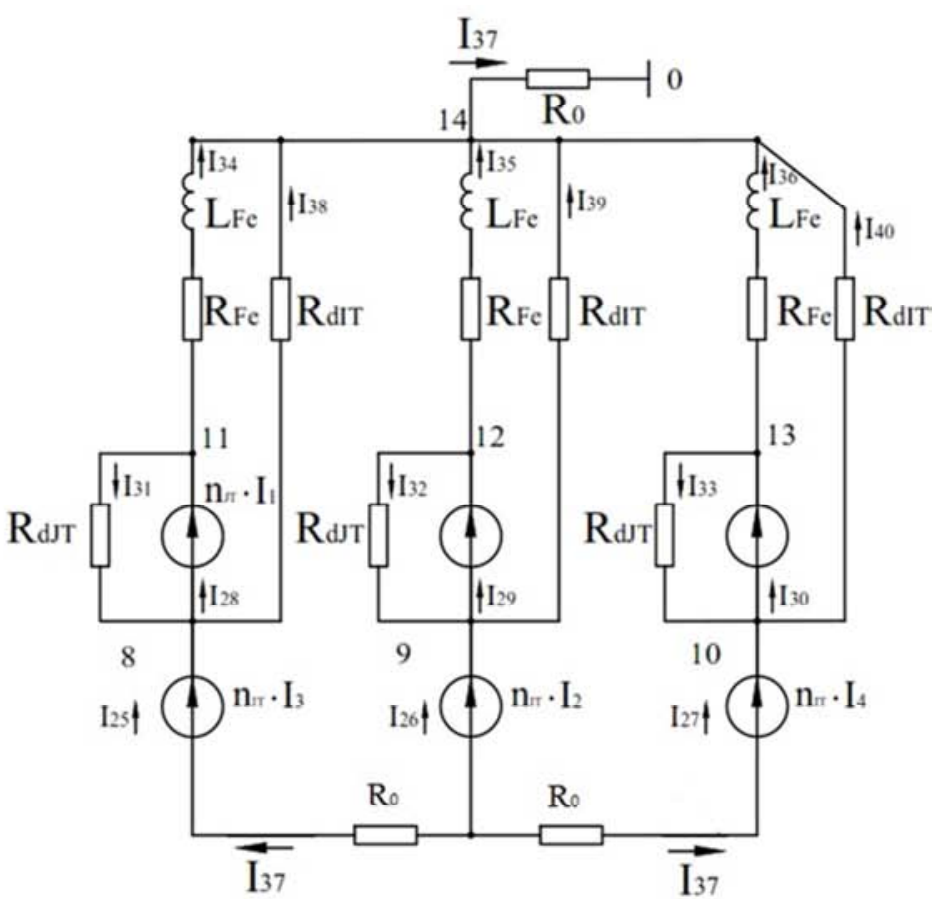

Figure 2. Coupled circuits model.

The following approximations were made, to calculate the leakage reluctances:

1. the first hypothesis is that the magnetic field lines are parallel to the winding generators and have a length equal to the height of the magnetic core window. This approximation is acceptable if we consider that the lines which are closed through the tank do not affect the magnitude of the leakage inductance significantly [11]. 
2. the second hypothesis is that the magnetic field lines only cross the path between the coils of the high-voltage, respectively low voltage windings, considering that the flux does not penetrate the core of the coils.

The second hypothesis assumes that path between the HV winding and the LV winding is equally filled by the lines of the magnetic field generated by the LV winding. These approximations are used for the calculation of the leakage reluctance between windings by using the following relations [8-10]:

$$
\begin{aligned}
& R_{d J T}=\frac{l_{F e}}{\mu_{0} \cdot \pi \cdot \frac{a}{2}\left(D_{F e}+2 a_{J T}+\frac{a}{2}\right)} \\
& R_{d I T}=\frac{l_{F e}}{\mu_{0} \cdot \pi \cdot \frac{a}{2}\left(D_{F e}+2 a_{J T}+\frac{3 a}{2}\right)}
\end{aligned}
$$

where:

$\mathrm{a}_{\mathrm{JT}}$ represents the height of the low voltage winding; $\mathrm{a}_{\mathrm{IT}}$ - height of the high voltage winding;

$\mathrm{a}$ - the /path between the coils of the high and low voltage windings;

$\mathrm{D}_{m J T}$ - average diameter of a LV turn;

$\mathrm{D}_{m I T}$ - average diameter of a HV turn;

$\mathrm{D}_{\mathrm{Fe}}$ - diameter of the magnetic core column;

$\mathrm{l}_{\mathrm{Fe}}$ - height of the magnetic core column.

\subsection{The Model of the Magnetic Core with Concentrated Parameters}

The magnetic core model implemented in the magnetic circuit coupled with the electrical circuit was proposed in the papers [9-10] and consists of:

inductance $\mathrm{L}_{\mathrm{Fe}}$ replacing the magnetic reluctance $R_{m}$;

$$
L_{F e}=\frac{N^{2}}{R_{m}}
$$

resistance $\mathrm{R}_{\mathrm{Fe}}$ replacing the magnetic inductance $\mathrm{L}_{\mu}$;

$$
R_{F e}=\frac{N^{2}}{L_{\mu}}
$$

where $\mathrm{N}$ is the number of turns of the primary.

$$
\begin{gathered}
R_{m}=\frac{l_{F e}}{\mu \cdot S_{F e}} \\
L_{\mu}=\frac{1}{\omega} \frac{U_{1 N}}{I_{\mu}} \approx \frac{1}{\omega} \frac{U_{1 N}}{1,04 \cdot I_{10}}
\end{gathered}
$$

where: $1_{\mathrm{Fe}}$ - length of the magnetic circuit;

$\mathrm{S}_{\mathrm{Fe}}$ - magnetic core section;

$\mu$ - relative permittivity;
$\Omega$ - the ripple of the transformer operating voltage is calculated by taking into consideration the fact that the frequency corresponding to the standard front of the lightning impulse is of approximately $15 \mathrm{kHz}$;

$\mathrm{U}_{1 \mathrm{~N}}$ - rated voltage of the primary;

$1,04 \cdot \mathrm{I}_{10^{-}}$the no-load current adjusted by an increase determined by the paper, related to the additional core losses, generated by the lightning impulse.

Another parameter introduced to the magnetic circuit model is the homopolar reluctance $\mathrm{R}_{0}$. The exact calculation of the homopolar reluctance is not possible because of the reluctance of the tank, which is in series with the reluctance of the oil flow path [12].

The proposed calculation relation does not include the reluctance of the tank [8-10]

$$
R_{0}=\frac{h_{c v}-h_{c m}}{\mu_{0} \cdot l_{c m} \cdot L_{c m}}
$$

where: $h_{c v}$ represents the average height of the tank;

$\mathrm{h}_{\mathrm{cm}}$ - average height of the magnetic circuit;

$1_{\mathrm{cm}}$ - average height of the magnetic circuit;

$\mathrm{L}_{\mathrm{cm}}$ - length of the magnetic circuit.

Table 1. Transformer parameters.

\begin{tabular}{ll}
\hline $\mathbf{R}_{\mathrm{IT}}=\mathbf{0 , 6 4} \cdot \mathbf{1 0}-\mathbf{3} \boldsymbol{k} \boldsymbol{\Omega}$ & $\mathbf{C}_{\mathrm{ITN}-\mathrm{IT}}=\mathbf{2 , 3} \mathbf{n F}$ \\
\hline $\mathrm{R}_{\mathrm{JT}}=3,67 \cdot 10^{-6} \mathrm{k} \Omega$ & $\mathrm{C}_{\mathrm{N}}=2,56 \mathrm{nF}$ \\
$\mathrm{n}_{\mathrm{IT}}=843$ & $\mathrm{C}_{\mathrm{JT}-\mathrm{C}}=3,44 \mathrm{nF}$ \\
$\mathrm{n}_{\mathrm{JT}}=72$ & $\mathrm{R}_{\mathrm{dJT}}=2,8 \cdot 10^{4} \mathrm{k} \Omega$ \\
$\mathrm{C}_{\mathrm{ITC}-\mathrm{TT}}=1,05 \mathrm{nF}$ & $\mathrm{R}_{\mathrm{dIT}}=2,7 \cdot 10^{4} \mathrm{k} \Omega$ \\
$\mathrm{C}_{\mathrm{IT} 2-\mathrm{C}}=0,48 \mathrm{nF}$ & $\mathrm{R}_{\mathrm{Fe}}=176 \mathrm{k} \Omega$ \\
$\mathrm{C}_{\mathrm{IT} 1 \mathrm{IT}}=0,47 \mathrm{nF}$ & $\mathrm{L}_{\mathrm{F}}=300 \mathrm{mH}$ \\
$\mathrm{C}_{\mathrm{IT} 3-\mathrm{TT}}=0,59 \mathrm{nF}$ & $\mathrm{R}_{0}=183,6 \mathrm{k} \Omega$ \\
$\mathrm{C}_{\mathrm{TT}-\mathrm{JT}}=1 \mathrm{nF}$ & \\
\hline
\end{tabular}

By modifying the various parameters of the coupled circuits, their influence on the results was revealed, which led to the following conclusions:

1. the influence of the relative permittivity/dielectric coefficient of the magnetic core is manifested through the modification of the amplitude of the voltage transmitted, i.e. its increase results in the decrease of the amplitude;

2. the frequency of response is indicated by the leakage inductance of the HV winding (which is energized by the lightning impulse) and its capacitance to ground.

\subsection{Results of the Modeling and Measurement of the Overvoltages Transmitted Between the Windings of Transformers}

To determine the overvoltages transmitted between the windings of the transformer, a study was conducted on a 40 MVA, $123 / 6.3 \mathrm{kV}$ TTOS-OFAF transformer.

The study includes both the simulations performed using the MATLAB program, as well as laboratory tests. In both the simulations and the tests, the impulse applied to the transformer is of $100 \mathrm{kV}(1.2 / 50 \mu \mathrm{s})$ [13-14]. 

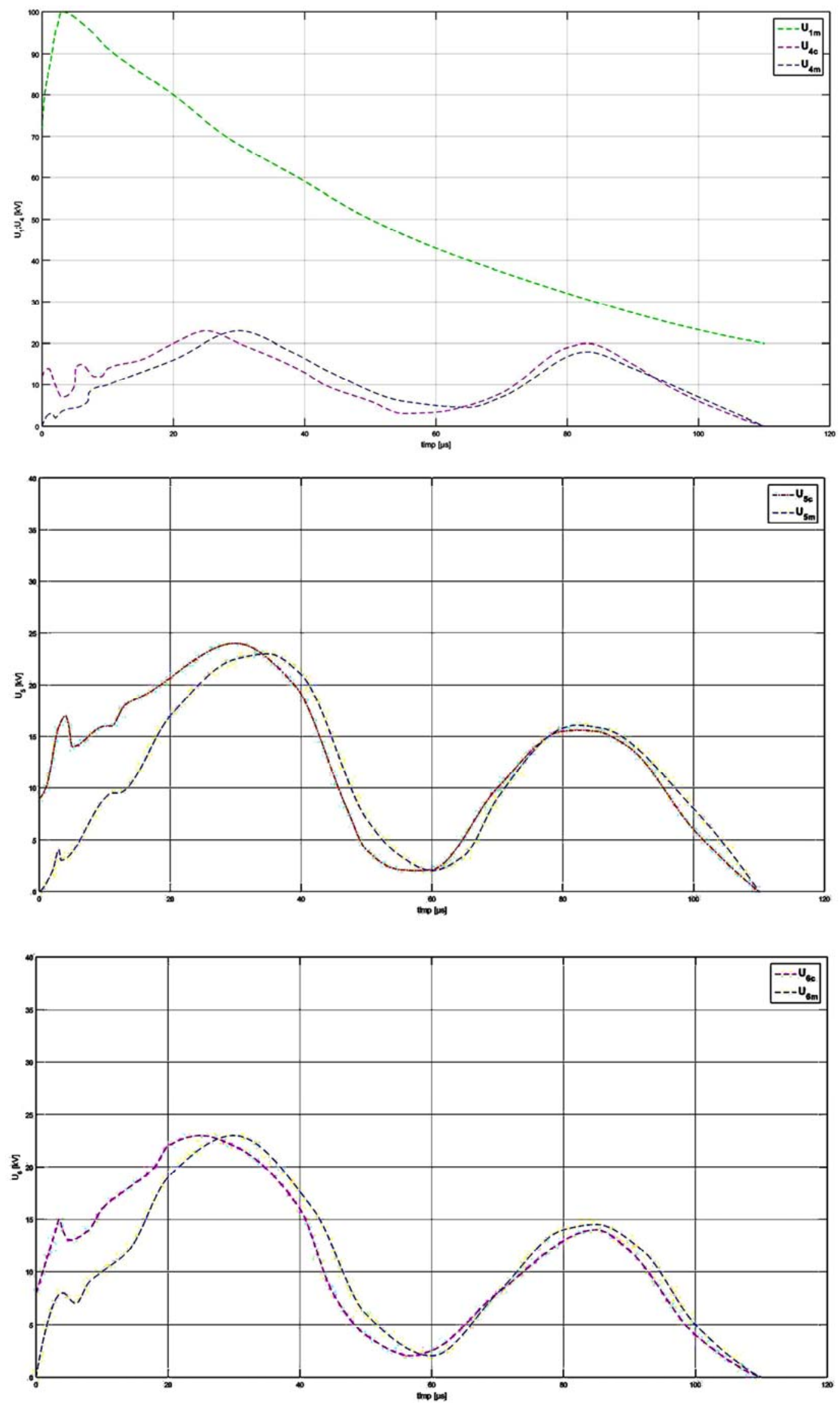

Figure 3. Voltage waveforms obtained by calculation and laboratory tests. 
Figure 3 shows the waveforms obtained by modeling and testing.

1. during the first microseconds, the calculated wave has a much faster front as opposed to the measured wave, which means that the model's capacitive network has a higher value than the actual one. A possible cause is the non-inclusion of the high-voltage winding series capacitance in the model created;

2. the difference in the maximum amplitude and its time of occurrence between the calculated and the measured response is insignificant. This parameter is essential, both for the designing engineers of transformers and for the designing engineers of the substations where the transformer will be implemented, for the protections rating;

3. the low and high frequencies are practically the same in the measured and calculated response;

4. the attenuation of the calculated signal is similar to that of the measured signal.

It can be seen in Table 2 that the relative error between the analytical and the practical method is less than about $1 \%$.

Table 2. Overvoltages-calculated values/measured values.

\begin{tabular}{lll}
\hline & $\mathbf{U}[\mathbf{k V}]$ & Relative error [\%] \\
\hline $\mathrm{U}_{4 \mathrm{~m}}$ & 23,09 & 0,47 \\
$\mathrm{U}_{4 \mathrm{c}}$ & 22,98 & \\
$\mathrm{U}_{5 \mathrm{~m}}$ & 23,96 & 0,29 \\
$\mathrm{U}_{5 \mathrm{c}}$ & 24,03 & \\
$\mathrm{U}_{6 \mathrm{~m}}$ & 23,20 & 1,16 \\
$\mathrm{U}_{6 \mathrm{c}}$ & 22,93 & 1,16 \\
\hline
\end{tabular}

$\mathrm{U}_{4 \mathrm{~m}}, \mathrm{U}_{5 \mathrm{~m}}, \mathrm{U}_{6 \mathrm{~m}}-$ measured transmitted overvoltages / $\mathrm{U}_{4 \mathrm{c}}, \mathrm{U}_{5 \mathrm{c}}, \mathrm{U}_{6 \mathrm{c}}$ calculated transmitted overvoltages.

\section{The Inrush Current Generated on High-power Transformer Wiring}

When wiring the transformer, a high transient current (inrush current) is generated in its windings, which can reach values of up to 10 times the load current. The shock produced by the magnitude of this current can lead to the disconnection of the transformer or to failure conditions.

The factors influencing the magnitude of the input current are: the remanent flux in the core of the transformer, the nonlinear magnetization characteristics of the transformer core, the phase angle of the supply voltage at the moment of the transformer energization, the impedance and the short-circuit power of the power supply etc [15-17].

The laboratory tests conducted in order to quantify the peak value of the inrush current, to prevent some situations of failure require great expense and are not being performed. For this reason, analytical methods and the simulation of the phenomenon were used to determine the magnitude of the transient current generated when wiring the transformer, to avoid possible damage and to choose the adequate protections [18-25].

An analysis is presented below on the transient phenomena generated by wiring the transformer, which leads to overload.

\subsection{Analytical Method for Determining the Inrush Current}

In the case of the transitory regime resulting from closing the circuit-breaker which wires the transformer, the current can reach values of up to five times the value of the rated current. In order to determine the inrush current, we apply at the terminals a sinusoidal voltage of the form $[9,22]$ :

$$
u_{1}=\sqrt{2} U_{1} \sin (\omega t+\alpha)
$$

where: $\mathrm{u}_{1}$ - is the voltage applied to the primary at time 0 ;

$\alpha$ - the initial phase angle.

The peak value of the inrush current and the flux depend on the output of the voltage applied at the time of connection (defined by $\alpha$ ).

The equation for the operation of the primary is $[9,22]$ :

$$
u_{1}=r_{1} i_{10}+w_{1} \frac{d \phi_{1}}{d t}
$$

where: $r_{1}$ - primary resistance;

$\mathrm{i}_{10}$ - inrush current;

$\mathrm{w}_{1}$ - number of turns in the primary;

$\varphi_{1}$ - the transformer no-load connection flux (fascicular flux); we will consider, for this study, that this flux flows through all the serial turns of the winding and that it is located in the gap.

The equation (20) can be written as a relation between the inrush current and the flux, using the inductance $[9,22]$ :

$$
L_{1} i_{1}=w_{1} \phi_{1}
$$

where: $\mathrm{L}_{1}$ - total inductance, variable within certain limits, depending on the magnetic saturation of the iron.

The equation of the instantaneous flux is expressed by the relation $[9,22]$ :

$$
\phi_{1}=\phi_{1 m}\left[\cos \alpha e^{-\frac{t}{\tau}}-\cos (\omega t+\alpha)\right]+\phi_{1 r e m} e^{-\frac{t}{\tau}}
$$

where: $\varphi_{1 \mathrm{~m}}$ is the maximum flux which depends on the value of the no-load current,

$\tau$ - winding time constant.

The total inductance $\left(\mathrm{L}_{1}\right)$ is considered as the sum of the leakage inductance and the magnetization inductance in the first moments of the connection, and, at the time of the magnetic core saturation, its value is considered as the equivalent of the leakage inductance.

The total resistance $\left(R_{1}\right)$ represents the sum of the high voltage winding resistance and the iron loss resistance at the time of the transformer wiring, and then it is considered as the value of the high voltage winding resistance.

For this study, we will consider that the transformer has not been previously wired, so the remanent flux $\left(\varphi_{1 \mathrm{rem}}\right)$ is zero. 
According to the studies presented in the literature, there are two extreme situations:

1. the first situation is characterized by a zero remanent flux and a supply voltage connection angle $\alpha=90^{\circ}$, a situation which corresponds to the stationary regime;

2. the second situation is characterized by a remanent flux equal to half the value of the maximum magnetization flux and a zero supply voltage connection angle.

This last situation is the most unfavorable, the wiring of the transformer is made at the zero cross-over voltage, and the remanent flux is of the opposite sign to the permanent flux. The value of the inrush current is maximum, causing shocks that in time result in damage to the transformer insulation.

\subsection{Results of the Modeling and Measurement of the Transformer Inrush Current}

The study was conducted on a 15 MVA, 10.5/6.3 kV TTOS-OFAF transformer.
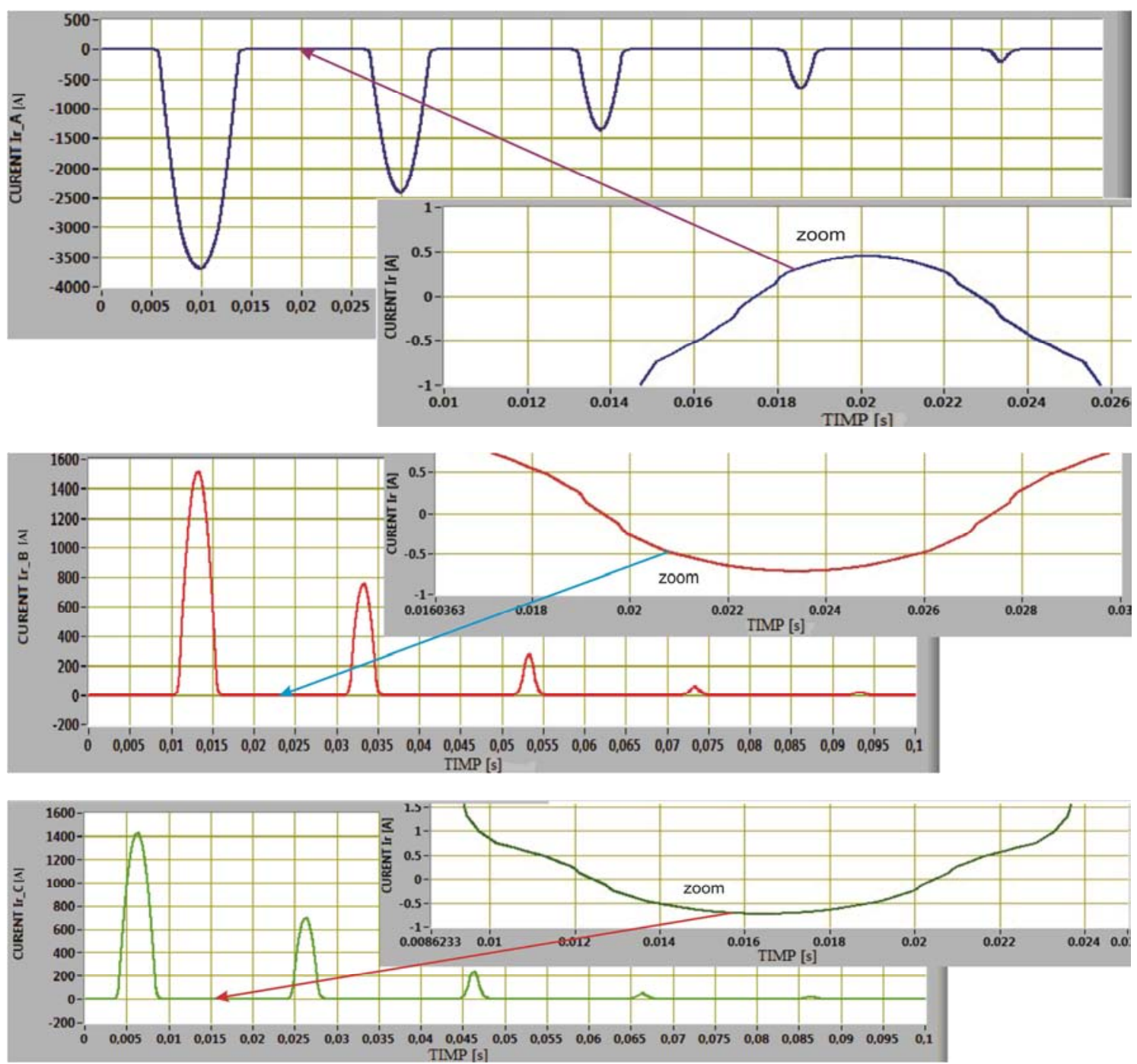

Figure 4. Waveforms for the inrush current on the three phases of the transformer obtained by modeling

Figure 4 shows the waveforms obtained by modeling; it can be noted that the peak value of the current is recorded on phase $\mathrm{A}$, at the zero cross-over voltage.

The relative error between the analytical and the practical method is less than $1,5 \%$.

The experimental results presented for the determination of the high-power transformer inrush current validate the theoretical study and are consistent with the simulation results.

The following conclusions can be reached:
1. the transitory regime which occurs when wiring the transformer lasts for a few seconds, after which it is attenuated

2. when wiring the transformer to the terminals of phase $A$ at the initial moment, there is zero-crossing voltage and the most important current shock is recorded;

3. the size of the current which occurs when wiring the transformer is dependent on the moment of the transformer wiring, i.e. by the value of the supply voltage connection angle. 


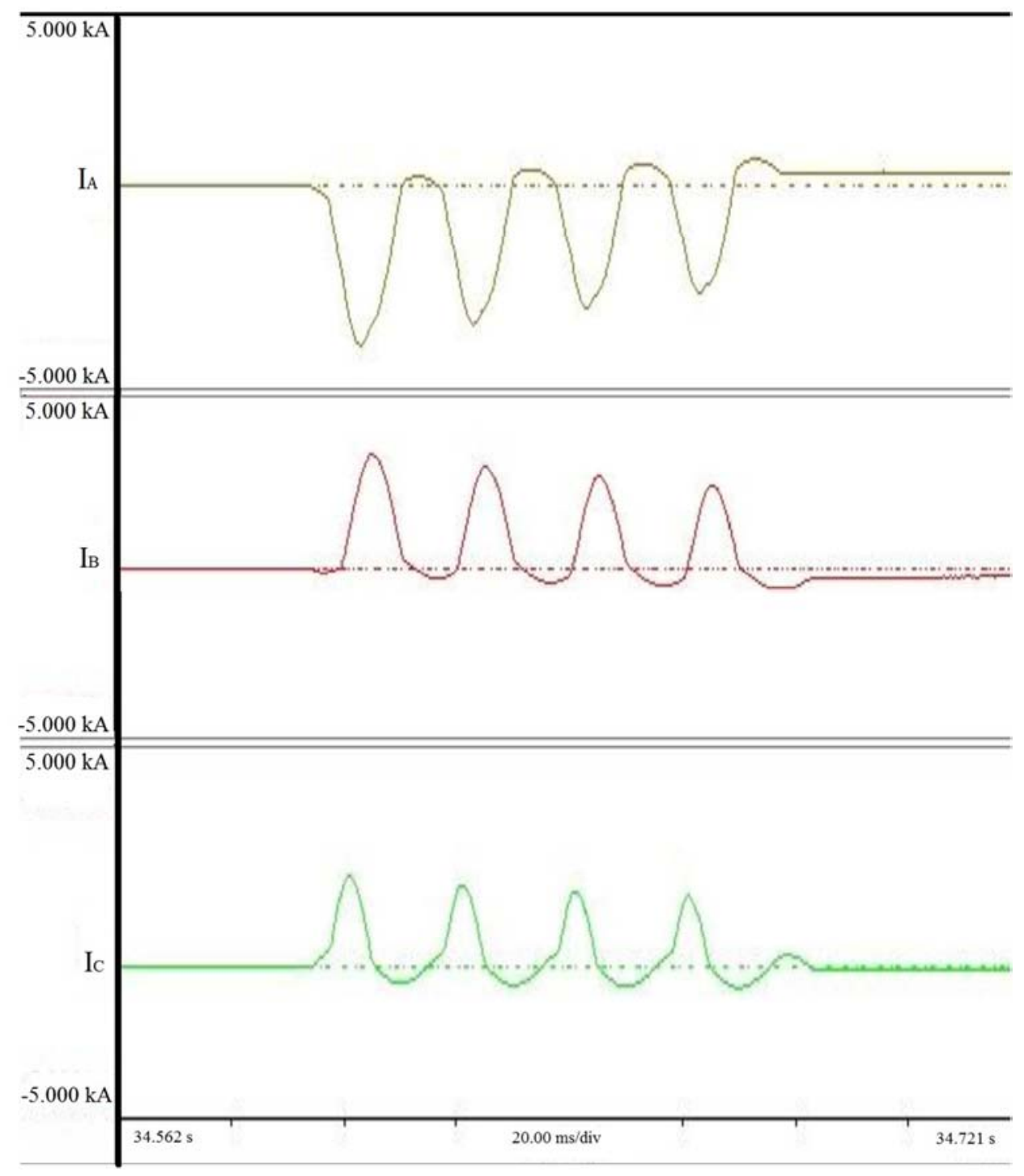

Figure 5. Waveforms for the inrush current on the three phases of the transformer obtained by measurement.

Table 3. Currents- calculated values/measured values [04].

\begin{tabular}{lll}
\hline & $\mathbf{I}[\mathbf{k A}]$ & Relative error [\%] \\
\hline $\mathrm{I}_{\mathrm{Am}}$ & 3,728 & 0,85 \\
$\mathrm{I}_{\mathrm{Ac}}$ & 3,696 & \\
$\mathrm{I}_{\mathrm{Bm}}$ & 1,534 & 1,4 \\
$\mathrm{I}_{\mathrm{Bc}}$ & 1,512 & \\
$\mathrm{I}_{\mathrm{Cm}}$ & 1,417 & 1,34 \\
$\mathrm{I}_{\mathrm{Cc}}$ & 1,398 & \\
\hline
\end{tabular}

$\mathrm{I}_{\mathrm{Am}}, \mathrm{I}_{\mathrm{Bm}}, \mathrm{I}_{\mathrm{Cm}^{-}}$currents measured on the 3 phases $/ \mathrm{I}_{\mathrm{Ac}}, \mathrm{I}_{\mathrm{Bc}}, \mathrm{I}_{\mathrm{Cc}^{-}}$currents calculated on the 3 phases.

\section{Conclusions}

The analysis carried out in this paper for the extreme dielectric and mechanical stresses generated in the case of transitory regimes such as overvoltages caused by lightning impulse and transient currents when wiring the transformer aims to predetermine by calculation the overvoltages and the transient currents propagating in the transformer windings.

Mathematical models were developed to determine the behavior of the transformer in case of overvoltage / overcurrent loads.

Based on these mathematical models presented, it was possible to observe which are the parameters that characterize and influence the transient phenomenon (overvoltage / inrush current).

The obtained results, following the mathematical modeling, were validated by laboratory tests, so the efficiency of the proposed methods is guaranteed.

The presented methods can be used to create an overview of the transformer behavior in case of a transient phenomenon, but also to adopt optimal solutions to avoid possible failures in the implementation of the transformer in the system.

\section{Acknowledgements}

The paper was developed with funds from the Ministry of Scientific Research of Romania, as part of the NUCLEU Program: PN 19380201 and PN 19380103. 


\section{References}

[1] Condition assessment of power transformers, in Cigré brochure 761, pp. 1-163, March 2019.

[2] S. Jazebi, F. de León and N. Wu, "Enhanced Analytical Method for the Calculation of the Maximum Inrush Currents of Single-Phase Power Transformers," in IEEE Transactions on Power Delivery, vol. 30, no. 6, pp. 2590-2599, Dec. 2015.

[3] Q. Guo, J. Wang, F. Zheng, G. Du, L. Zhu and J. Guo, "An Application of Inrush Current Suppression Technology Based on CNN in Switching Operation of High-voltage Built-in High-impedance Transformer," 2018 IEEE Innovative Smart Grid Technologies - Asia (ISGT Asia), Singapore, 2018, pp. 511-516.

[4] P. C. Y. Ling and A. Basak, "Investigation of magnetizing inrush current in a single-phase transformer," in IEEE Transactions on Magnetics, vol. 24, no. 6, pp. 3217-3222, Nov 1988.

[5] S. De and A. De, "Low cost surge voltage linearization methods for small rating power transformers," 2017 IEEE Calcutta Conference (CALCON), Kolkata, 2017, pp. 69-73.

[6] Y. Zhou et al., "A Model Considering Deep Saturation of the Iron Core for $10 \mathrm{kV}$ Potential Transformers," 2018 IEEE International Conference on High Voltage Engineering and Application (ICHVE), ATHENS, Greece, 2018, pp. 1-4,

[7] Zhong Yuan Zhang, Xin Ge, Zeng Chao Wang, "Research on Nonlinear Modeling for Power Transformer over Wide Frequency Range", Applied Mechanics and Materials, vol. 446-447, pp. 832, 2013.

[8] S. V. Kulkarni, S. A. Khaparde, "Transformer Engineering: Design and Practice", Marcel Dekker, 2004.

[9] I. Gheorghiu, A. Fransua, "Maşini electrice", vol. II. Editura Academiei Republicii Socialiste Romania, 1970.

[10] Maria Cristina Nițu, Marian Duță, "Calculation of Surges Transmitted Between Transformer Windings Using the Coupled Circuit Model", Proceedings of the International Conference on Applied and Theoretical Electricity (ICATE), Craiova, Romania, 4-6 October, 2018, pp. 1-6.

[11] C. M. Arturi, "Transient Simulation and Analysis of a Five-Limb Step-Up Transformer Following and Out-of-Phase Synchronization", IEEE Transactions on Power Delivery, Vol. 6, No. 1, January 1991, pp. 196-207.

[12] P. I. Fegerstad, T. Henriksen, "Inductance for the Calculation of Transient Oscillation in Transformers", In: IEEE Transactions on Power Apparatus and Systems, vol. PAS-93, pp. 510-517, March/April 1974.

[13] ***IEC 60076-1: 2011-Power Transformer. Part. 1-General.

[14] ***IEC 60076-3: 2013-Power Transformer. Part. 3-Insulation levels, dielectric tests and external clearances in air.
[15] Maria-Cristina Nițu, Claudiu-Ionel Nicola, Marcel Nicola, Marian Duță, "Determination of Inrush Current to High Power Transformers using the LabVIEW Environment", Journal of Mechanical Engineering and Automation, Vol. 7, No. 2, 2017, pp. 46-52, USA.

[16] Maria Cristina NIȚU, Marian DUȚĂ, Claudiu-Ionel NICOLA, "Predetermining the size of inrush current in power transformers coupling using LabVIEW", Proceedings of International Conference on Hydraulics and Pneumatics HERVEX - 22nd edition, Băile Govora, 9-11 November 2016, pp. 271-279.

[17] Michael Streuer, Klaus Fröhlich, "The Impact off Inrush Currents on the Mechanical Stress of High Voltage Power Transformer Coils", In: IEEE Transactions on Power Delivery, vol. 17, No. 1, pp. 155-160, Ianuary 2002.

[18] Yu Cui, Sami G. Abdulsalam, Shiuming Chen, Wilsun Xu, "A sequential phase energization technique for transformer inrush current reduction- Part I: Simulation and experimental results", IEEE Trans. on Power Delivery, vol. 20, no. 2, pp. 943-949, April 2005.

[19] Wilsun Xu, Sami G. Abdulsalam, Yu Cui, Xian Liu, "A sequential phase energization technique for transformer inrush current reduction- Part II- Theoretical analysis and design guide”, IEEE Trans. on Power Delivery, vol. 20, no. 2, pp. 950-957, April 2005

[20] Wilsun Xu, Sami G. Abdulsalam, "A sequential phase energization method for transformer inrush current reduction- transient performance and practical considerations", IEEE Trans. on Power Delivery, vol. 22, no. 1, pp. 208-216, January 2007.

[21] M. G. Vanti, S. L. Bertoli, S. H. Cabral, A. G. Gerent, P. Kuo-Peng, "Semianalytic solution for a simple model of inrush currents in transformers", IEEE Trans. on Magnetics, vol. 44, no. 6, pp. 1270-1273, June 2008.

[22] Maria Cristina NIȚU, V. Voicu, M. Duță, P.-M. Nicolae, "Ensuring the Security of the Energy System by Predetermining the Size of Inrush Current at Power Transformers Coupling ", In Proc. of 16th - International Conference on Computer as a Tool- EUROCON, Salamanca, Spania, pp. 1-4, September 2015.

[23] Hong, L. Haifeng, L. Hua, Z. Jiran, T. Haiguo and Z. Zhidan, "Waveform Complexity Analysis of Differential Current Signal to Detect Magnetizing Inrush in Power Transformer," 2017 9th International Conference on Measuring Technology and Mechatronics Automation (ICMTMA), Changsha, 2017, pp. 120-123.

[24] A. YAHIOU, A. BAYADI and B. BABES, "Point on Voltage Wave Switching for Sympathetic Inrush Current Reduction.," 2018 International Conference on Applied Smart Systems (ICASS), Medea, Algeria, 2018, pp. 1-4.

[25] S. S. H. Bukhari, M. Gul and F. A. Chachar, "A Series Voltage Sag Compensator with Reduced Magnitude of Transformer Inrush Current," 2018 IEEE 4th Southern Power Electronics Conference (SPEC), Singapore, Singapore, 2018, pp. 1-4. 